\title{
ATITUDES PEDAGÓGICAS DE PROFESSORES UNIVERSITÁRIOS DE INGLÊS EM MEIO À PROLIFERAÇÃO DE ACRÔNIMOS PARA A LÍNGUA INGLESA ${ }^{1}$
}

\section{PEDAGOGICAL ATTITUDES OF ENGLISH LANGUAGE PROFESSORS AMID THE PROLIFERATION OF ACRONYMS FOR THE ENGLISH LANGUAGE}

\author{
Regina Celia Halu ${ }^{2}$
}

\begin{abstract}
RESUMO: O objetivo desta pesquisa qualitativa é investigar as atitudes pedagógicas que docentes pesquisadores universitários atuando na formação de professores de inglês estão desenvolvendo em face aos debates em torno do status da língua inglesa hoje. Para tanto, considero os relatos dos professores participantes, obtidos por meio de entrevistas semiestruturadas, como parte de suas trajetórias identitárias profissionais, inseridas em diferentes comunidades (WENGER, 1988). Como base teórica principal, adoto de Wenger (1988) o conceito de identidade como nexo de trajetórias de aprendizagem pela prática social, de linguagem como discurso (FOUCAULT, 2000) e de atitude tal como utilizado por Duboc (2012). A interpretação dos dados, ao examinar o entrelaçamento entre trajetórias profissionais e construção de atitudes pedagógicas frente às mudanças envolvendo a língua inglesa hoje, enfoca duas tendências: uma em que se desenvolvem atitudes diferentes na pesquisa e no ensino, continuando trajetórias como pesquisadores dentro da tradição que toma, explicita ou implicitamente, o falante nativo como pressuposto teórico, ao mesmo tempo em que na docência problematizam as noções de língua padrão e do nativo como baliza natural para o aprendizado; e outra em que há uma aproximação das atitudes nos dois campos, com esforços para encaminhar tanto a pesquisa quanto a docência considerando as mudanças de status do inglês e as críticas a conceitos como o de falante nativo.
\end{abstract}

PALAVRAS-CHAVE: Expansão da língua inglesa. Falante nativo. Professores universitários de inglês. Atitude. Trajetória identitária profissional.

ABSTRACT: The aim of this qualitative research is to investigate the pedagogical attitudes that university research professors who work in the area of initial English language teacher education are developing in face of the debates around the status of the English language today. Therefore, I consider the participant professors' answers to semi-structured interviews as part as their professional identitary trajectories, within different communities (WENGER, 1988). As theoretical basis, I adopt Wenger's concept of identity (1988) as a nexus of learning trajectories, built through social practices, language as discourse (FOUCAULT, 2000) and attitude as used by Duboc (2012). The interpretation of the data, when examining the intertwining of professional trajectories and the construction of pedagogical attitudes in face of the changes involving the English language today, focuses on two tendencies: one in which the researcher professor develops different attitudes for research and teaching, continuing their trajectories as researchers within the tradition that takes, explicitly or implicitly, the native speaker as theoretical assumption, whereas in their teaching practice they problematize the notions of standard language and the native speaker as the natural learning goal; and another in which there is an approximation of the attitudes in these two fields, striving to develop both their research and their teaching taking into consideration the changes in the status of English and the criticism to concepts such as the native speaker.

KEYWORDS: Expansion of the English language. Native speaker. Professors of English. Attitude. Professional identitary trajectory.

\section{Introdução}

Muito se fala sobre a formação de futuros professores de inglês no Brasil e no mundo e sobre os desafios que enfrentam em tempos de glocalização e mudanças no status da língua inglesa (EL KADRI, 2010; GIMENEZ et al., 2011; SIQUEIRA, 2018; CANAGARAJAH, 2014; BROWN, MCKAY, 2016). No mundo acadêmico, novas terminologias são apresentadas

\footnotetext{
${ }^{1}$ Este texto é resultado de pesquisa desenvolvida durante estágio pós-doutoral, realizado entre agosto de 2017 e julho de 2018, sob supervisão da Prof ${ }^{\text {a. }}$ Dra. Gloria Gil, do Programa de Pós-Graduação em Inglês da Universidade Federal de Santa Catarina.

2 Professora Associada da Universidade Federal do Paraná, junto ao Departamento de Letras Estrangeiras Modernas (DELEM). E-mail: reginah@ufpr.br.
} 
com a intenção de oferecer novos entendimentos sobre o papel e status do inglês em um mundo em que a natureza multi e trans das línguas e seus linguajantes entra em conflito com o ideal monolíngue próprio dos estados-nações (JORDÃO, 2009, 2014; JENKINS, 2015). Trabalhando na Universidade Federal do Paraná (UFPR), na formação inicial e continuada de professores de língua inglesa no curso de Letras, percebi que o contato com esses diferentes discursos gerou insegurança quanto a minha atuação em sala de aula uma vez que eles questionam os pressupostos nos quais foi construída boa parte da base teórica sobre o ensino e aprendizagem de línguas. Essa situação me levou a perguntar como outros professores pesquisadores, meus colegas, lecionando inglês em nossas universidades e preparando nossos futuros professores, estariam reagindo. Desejei investigar as atitudes pedagógicas que nós, docentes pesquisadores atuando na formação de professores de inglês, estávamos desenvolvendo e negociando em meio ao labirinto de ILI, ILF, LFI, ILA, ILE, IM ILG e demais possíveis acrônimos ${ }^{3}$. Fiquei interessada não em investigar as diferenças conceituais entre os termos emergentes e suas consequências discursivas ${ }^{4}$, mas em observar, como parte da formação de nossas trajetórias identitárias profissionais na universidade, o que construímos e modificamos nas nossas atitudes pedagógicas quanto ao ensino de inglês e à formação de professores de inglês no contexto atual.

$\mathrm{O}$ que permitiu transformar essa pergunta em um projeto de pesquisa foi um contexto de trabalho especialmente favorável. $\mathrm{Na}$ esfera nacional, um momento positivo de compartilhamento de pesquisas e experiências docentes por meio de diversos congressos (incluindo o Congresso Mundial de Linguística Aplicada da AILA em 2017 no Rio de Janeiro, as edições do CLAFPL, dos congressos da ABRAPUI, e mais recentemente do ICCAL $^{5}$ ) e publicações voltadas para o tema (BORDINI, GIMENEZ, 2014; GIMENEZ et al., 2018). Dentro da UFPR, os docentes da área de inglês encontravam-se atentos aos desafios de como atuar em sala de aula considerando a mudança no status da língua inglesa. Nos grupos de pesquisa debatíamos diferentes visões e opções de práticas pedagógicas e na pós-graduação alguns de nós aprofundavam a reflexão sobre o tema em suas disciplinas, com consequentes publicações (FIGUEIREDO, 2018a, 2018b; FIGUEIREDO, SANFELICI, 2017; FOGAÇA, 2016; JORDÃO, MARTINEZ, 2015; MARTINEZ, 2018) Nesse contexto, o encontro com Gloria Gil ${ }^{6}$, professora pesquisadora na Universidade Federal de Santa Catarina (UFSC), viabilizou o estágio de pós-doutorado, dentro do qual inseri a pesquisa. Gil, que aceitou me supervisionar, também vinha pesquisando e orientando trabalhos que exploram as questões identitárias e pedagógicas surgidas com a expansão do inglês (REGIS, GIL, 2012; DENARDI, GIL, 2015; BERREDO, GIL, 2018; ROSA FILHO, VOLPATO, GIL, 2018).

\section{A pesquisa}

Meu trabalho de revisão bibliográfica na área contou com a colaboração fundamental do professor Dr. Eduardo Diniz de Figueiredo, atuante no Programa de Pós-Graduação em Letras da UFPR. Ele permitiu que eu acompanhasse as discussões online realizadas como parte da disciplina de Tópicos em Linguística Aplicada II, que ofertava no $2^{\circ}$. Semestre de 2017, a

\footnotetext{
${ }^{3}$ ILI corresponde a Inglês como Língua Internacional, ILF a Inglês como Língua Franca, ILA a Inglês como Língua Adicional, ILE a Inglês como Língua Estrangeira, IM a Ingleses Mundiais e ILG a Inglês como Língua Global. Ao longo do texto, uso por vezes os termos em inglês.

${ }^{4}$ Uma pertinente discussão sobre tais diferenças foi desenvolvida por Jordão (2014).

5 AILA é a Associação Internacional de Linguística Aplicada, CLAFPL é o Congresso Latino-Americano de Formadores de Professores de Línguas, ABRAPUI é a Associação Brasileira de Professores Universitários de Língua Inglesa e ICCAL corresponde a International Congress of Critical Applied Linguistics.

${ }^{6}$ A Prof ${ }^{\text {a. }}$ Dra. Gloria Gil é também coordenadora do grupo de pesquisa "Língua, cultura e identidade no ensino e aprendizagem de línguas adicionais".
} 
Volume 16 - Número 1 - jan/jul de 2021

qual tinha como foco as imbricações entre os estudos de aquisição de segunda língua e os de inglês como língua internacional. Dessa forma, recebi, além de acesso a leituras atualizadas e pertinentes, a oportunidade de compartilhar reflexões com os mestrandos e doutorandos participantes, que concordaram com minha presença no fórum virtual.

A pesquisa de campo envolveu a participação de docentes de duas universidades públicas brasileiras (designadas aqui apenas como Universidade A e Universidade B), atuando no ensino de língua inglesa para a formação inicial de professores de inglês. Realizei com elas entrevistas, com o objetivo de explorar suas atitudes pedagógicas em face da expansão do inglês e das teorizações sobre tal fenômeno, e consultei seus currículos (disponibilizados na Plataforma Lattes), verificando informações quanto as suas formações, atuações e publicações. Houve dois casos em que, devido à impossibilidade de encontro face à face, foi preciso recorrer a comunicação eletrônica (gravações e e-mail) para realizar essa parte da pesquisa, Foram quatro docentes de cada universidade (quatro docentes doutoras da Universidade A; duas docentes doutoras e duas docentes em doutorado da Universidade B). Com a intenção de manter o anonimato das participantes, evitei detalhar dados de perfil, atendo-me às informações mais pertinentes para o foco da pesquisa. Não houve a intenção de comparar os dois grupos de docentes; o objetivo era explorar a construção de atitudes pedagógicas quanto aos novos entendimentos sobre a língua inglesa no momento de expansão atual.

A geração das perguntas usadas na entrevista se iniciou com uma conversa informal com o professor Eduardo Figueiredo ao final do Congresso da AILA em 2017, e seu desenvolvimento se deu em meio às trocas de reflexões no fórum e à participação em bancas de qualificação e defesa de mestrado e doutorado em programas de pós-graduação. As perguntas também amadureceram ao realizar uma entrevista com o professor Dr. Francisco Carlos Fogaça ${ }^{7}$, meu colega na UFPR, sobre as mudanças em suas atitudes pedagógicas desde sua entrada na nossa instituição em 2009. Da entrevista inicial, ancorada em um artigo publicado com Cristina Mott-Fernandez (MOTT-FERNANDEZ, FOGAÇA, 2009), em que relatavam uma pesquisa sobre as crenças de alunos de Letras quanto ao ensino de inglês como língua internacional, nossas reflexões acabaram por se transformar em um diálogo, publicado na Revista X (HALU, FOGAÇA, 2018).

Essas são as perguntas que serviram de base para entrevistas semiestruturadas:

- Para tratar das diversas práticas de uso de língua inglesa hoje no mundo, uma série de termos têm sido oferecidos pelos pesquisadores - língua franca, língua internacional, língua global, inglês mundial, ingleses mundiais. Qual ou quais termos você considera mais adequado para tratar da língua inglesa hoje, considerando em especial o contexto brasileiro e as consequências para o ensino e para a formação de professores?

- Quando você primeiro entrou em contato com a discussão sobre o novo status do inglês no mundo globalizado? Essas discussões afetaram suas reflexões e sua prática como pesquisadora e/ou docente? De que forma?

- Como você avalia, baseando-se em sua experiência na universidade, a adequação da formação oferecida para os alunos de Letras e do programa de pós-graduação, em especial para os futuros professores e formadores de professores, para os tempos de inglês em expansão mundial?

\section{Atitude pedagógica e trajetórias identitárias}

Para tratar da construção de atitudes pedagógicas por parte de docentes pesquisadores na área de Letras envolvidos com a formação de professores de inglês, iniciei com a base teórica

\footnotetext{
${ }^{7}$ Francisco Carlos Fogaça e eu compartilhamos a liderança do grupo de pesquisa "Formação de Professores de Línguas - UFPR".
} 
já utilizada por Machado e Gil (2017) em pesquisa sobre a construção identitária de docentes de língua inglesa. Elas aproximaram a noção de identidade profissional como uma construção narrativa, tal como exposto por Connelly e Clandinin (1999), da compreensão de que a formação dessas identidades se dá por meio de negociações em comunidades de práticas, a qual foi aprofundada por Wenger (1998). Além disso, salientaram a centralidade de práticas discursivas para a compreensão da participação em comunidades de prática, ancorando-se em Gee (2000), para quem

[...] a identidade é constituída nas experiências específicas do indivíduo dentro de discursos específicos e sua narrativização dessas experiências, o que permite ser reconhecido ou reconhecida como um certo tipo de pessoa em um dado tempo e lugar. O autor enfatiza que "[o] tipo de pessoa como o qual ela é reconhecida como 'sendo' num dado tempo e lugar pode mudar de um momento a outro na interação, pode mudar de um contexto a outro e, claro, pode ser ambíguo ou instável" (Gee, 2000, p.100). (MACHADO, GIL, 2017, p.387)

Apenas critico em Wenger o fato de que, apesar de mencionar a noção de discurso de Gee, ele acaba por afirmar que não considera os discursos como 'práticas nelas mesmas' (WENGER, 1998, p. 129) e segue tratando das práticas discursivas como parte do que entende por reificação, preferindo discutir a negociação de significados com a ajuda dos conceitos de participação e reificação ${ }^{8}$. Para ele, discursos, vistos de forma reificada, isto é, transformada como que em objetos, seriam "material disponível - recursos que podem ser usados no contexto de várias práticas" (WENGER, 1998, p.129). Quando Wenger conceitua identidade como “[...] um modo de falar sobre como o aprendizado muda quem somos e cria histórias pessoais de vir a ser no contexto de nossas comunidades", prefiro compreender que essas histórias são construídas por nós e que elas também nos constroem, uma vez que, como expresso por Foucault (2000, p.20-21), somos "seres de linguagem e não seres que possuem linguagem". Com a opção teórica de Wenger, linguagem e suas práticas (como a construção de "modos de falar" e a criação de histórias) acabam sendo abordadas somente como recursos ou como abstrações objetificadas.

Assim, de Wenger (1998, p.138), tomo o conceito de que a identidade pode ser compreendida como trajetórias de aprendizagem, no plural:

[u]ma identidade é assim mais do que somente uma única trajetória; ao invés disso, deveria ser vista como um nexo de multipertencimento. Como tal nexo, a identidade não é uma unidade, nem é tampouco simplesmente fragmentada. $[\ldots]$

Um nexo não merge as específicas trajetórias que formamos em nossas diversas comunidades em uma; mas também não decompõe nossa identidade em trajetórias distintas em cada comunidade. Em um nexo, múltiplas trajetórias tornam-se parte umas das outras, quer entrem em conflito ou reforcem umas às outras. São, ao mesmo tempo, uma e múltipla.

A forma como a sociedade em que vivemos vai se transformando e novos fenômenos surgem já em meio a uma rede de construções discursivas nas quais nos encontramos sendo interpelados quanto a nossos posicionamentos, interpelando ao outro com nossas respostas, e como esse responder e participar dessas construções se entrelaça com o desenvolvimento de nossas trajetórias identitárias, aqui em especial no campo da docência e pesquisa universitárias.

\footnotetext{
${ }^{8}$ Wenger apresenta seu uso do termo reificação no primeiro capítulo de Communities of Practice (1998, p. 57 62), como base para tratar da negociação de significados.
} 
No caso da expansão do uso do inglês no mundo e da proliferação de termos para se referir ao novo status dessa língua, chama a atenção como o pensar sobre tal fenômeno e o se posicionar quanto ao uso desses novos termos enreda-se na construção de narrativas de trajetórias profissionais.

Considerei que nessas narrativas seria possível observar a construção de atitudes pedagógicas e como elas vão se configurando em meio à participação em comunidades diversas. O que observei foi que elas existem também em relação a outras atitudes, como as que surgem nas práticas de pesquisa acadêmica. De qualquer forma, o conceito de atitude que tomei como guia foi aquele expresso por Duboc $(2012$, p. 101), em sua pesquisa sobre a prática pedagógica e a agência de professores dentro de disciplinas de um currículo universitário de Letras:

Atitude compreendida aqui como resposta (BIESTA, 2006; MENEZES DE SOUZA, 2011) $)^{9}$ o 'responder responsavelmente' imbuído no exercício de agenciamento. O conceito não abraça a ideia totalitária de transformação, mas a compreende como possibilidade.

Observei que os próprios momentos de reflexão compartilhada que caracterizam a participação em pesquisas como a minha, sobre temas e práticas de natureza pedagógica, constituem práticas que contribuem para a contínua construção de tais atitudes.

No caso das atitudes pedagógicas em resposta ao fenômeno da expansão do inglês, a escolha ou não de um termo ou outro (ILF, ILI, IM, etc.) depende da forma como as trajetórias profissionais de cada professor se entrelaçam em um dado momento. Somente a adoção de um termo ou a falta dele não diz muito, mas observar isso dentro das narrativas das participantes sobre seus caminhos como docentes, pesquisadoras e aprendizes de línguas permite construir uma visão de suas práticas e atitudes em dado momento e contexto.

\section{Discussão}

A primeira e a segunda perguntas, junto com a análise dos currículos, permitiram conhecer as áreas principais de atuação docente e de pesquisa das participantes e observar a preferência terminológica para se referir ao inglês. O quadro a seguir traz um resumo desses dados:

\begin{tabular}{|l|l|l|l|}
\hline $\mathbf{P}$ & $\begin{array}{l}\text { Principais focos de } \\
\text { pesquisa }\end{array}$ & $\begin{array}{l}\text { Outras áreas de } \\
\text { atuação }\end{array}$ & Inglês em expansão: uso de termos \\
\hline $\mathbf{1}$ & $\begin{array}{l}\text { Formação de professores } \\
\text { de LE, língua e cultura, } \\
\text { língua e identidade }\end{array}$ & $\begin{array}{l}\text { Orientação publicação } \\
\text { de pesquisas sobre } \\
\text { língua e identidade, } \\
\text { ILA/ILE, ILF e } \\
\text { práticas/representações } \\
\text { de alunos e professores } \\
\text { de LI, coordenação de } \\
\text { centro de línguas }\end{array}$ & $\begin{array}{l}\text { ILF, ILA, dependendo do contexto } \\
\text { Critica a distância entre discussões } \\
\text { terminológicas e as práticas de ensino de LI }\end{array}$ \\
\hline $\mathbf{2}$ & $\begin{array}{l}\text { Ensino e aprendizagem } \\
\text { de LE/L2 (viés } \\
\text { cognitivo), }\end{array}$ & $\begin{array}{l}\text { Participação em projeto } \\
\text { de extensão - ensino de } \\
\text { português para } \\
\text { imigrantes }\end{array}$ & $\begin{array}{l}\text { Não utiliza nenhum termo especificamente } \\
\text { Reflexões na pesquisa e na prática docente } \\
\text { em torno dos conceitos de falante nativo, }\end{array}$ \\
\hline
\end{tabular}

\footnotetext{
${ }^{9}$ BIESTA, G. Beyond Learning: democratic education for a human future. London: Paradigm Publishers, 2006. MENEZES DE SOUZA, L. M. T. Para uma redefinição de Letramento Crítico: conflito e produção de Significação. In: MACIEL, R. F.; ARAUJO, V. A. (Orgs.) Formação de Professores de Línguas: ampliando perspectivas. Jundiaí: Paco Editorial, 2011.
} 
Volume 16 - Número 1 - jan/jul de 2021

\begin{tabular}{|c|c|c|c|}
\hline & $\begin{array}{l}\text { aprendizagem } \\
\text { colaborativa, task based } \\
\text { learning }\end{array}$ & & $\begin{array}{l}\text { inteligibilidade, legitimidade e de } \\
\text { consideração dos contextos de uso }\end{array}$ \\
\hline 3 & $\begin{array}{l}\text { Metodologia de pesquisa } \\
\text { em LA } \\
\text { Fonologia da LI }\end{array}$ & $\begin{array}{l}\text { Participação em projeto } \\
\text { de extensão - ensino de } \\
\text { português para } \\
\text { imigrantes }\end{array}$ & $\begin{array}{l}\text { ILI, refletindo sobre conceitos de falante } \\
\text { nativo, inteligibilidade, legitimidade e } \\
\text { sobre contexto sócio-histórico }\end{array}$ \\
\hline 4 & $\begin{array}{l}\text { Fonologia e aquisição de } \\
\text { LE }\end{array}$ & $\begin{array}{l}\text { participação em projeto } \\
\text { de extensão - ensino de } \\
\text { português para } \\
\text { imigrantes }\end{array}$ & $\begin{array}{l}\text { P não tem familiaridade com os termos. } \\
\text { Na pesquisa, mantém o foco na acurácia } \\
\text { relativa a uma língua padrão. No ensino, } \\
\text { apresenta variedades do inglês e diminui o } \\
\text { foco no falante nativo de português para } \\
\text { imigrantes }\end{array}$ \\
\hline 5 & $\begin{array}{l}\text { ILI, aquisição e ensino } \\
\text { de línguas, LA critica }\end{array}$ & $\begin{array}{l}\text { Escrita acadêmica } \\
\text { (projeto de extensão) }\end{array}$ & ILI \\
\hline 6 & $\begin{array}{l}\text { Formação de professores } \\
\text { de LE, análise do } \\
\text { discurso crítica, } \\
\text { multiletramentos, } \\
\text { letramento crítico }\end{array}$ & $\begin{array}{l}\text { Atuou na coordenação } \\
\text { pedagógica de centro de } \\
\text { línguas }\end{array}$ & Inglês glocal \\
\hline 7 & $\begin{array}{l}\text { Formação de professores } \\
\text { de LI, literaturas de LI, } \\
\text { tradução }\end{array}$ & $\begin{array}{l}\text { Coordenou o trabalho } \\
\text { de assistentes de ensino } \\
\text { Fullbright }\end{array}$ & World Englishes \\
\hline 8 & $\begin{array}{l}\text { Formação de professores } \\
\text { de LI, ensino e } \\
\text { aprendizagem de LI }\end{array}$ & $\begin{array}{l}\text { Coordenação do PIBID } \\
\text { inglês } \\
\text { Assessoria pedagógica } \\
\text { IsF }\end{array}$ & $\begin{array}{l}\text { Familiarizando-se com termos } \\
\text { Inglês global como uma opção no } \\
\text { momento }\end{array}$ \\
\hline
\end{tabular}

Quadro 1: Focos de pesquisa, áreas de atuação e preferência terminológica quanto à língua inglesa Fonte: A autora (2018).

Do conjunto de perguntas, foi possível observar algumas características comuns nas atitudes dos professores entrevistados. A prática pedagógica mais comum tem sido a inserção nas aulas de momentos de reflexão crítica sobre o status do inglês no mundo e os desafios consequentes para o ensino. Isso tem ocorrido tanto nas disciplinas específicas de inglês, como em disciplinas da área de LA e também em algumas de áreas mais tradicionais, como as voltadas para a gramática e fonologia da língua inglesa. Além de ocorrerem na graduação, também ocorrem nos projetos e eventos de extensão voltado para a formação continuada. Além disso, há mudança na atitude avaliativa e de correção na aprendizagem do inglês, mais flexível e oferecendo justificativas de escolhas linguísticas mais ou menos adequadas dependendo do contexto e gênero discursivo. Como expressa a participante 5, ao relatar sobre sua atuação em uma disciplina de língua inglesa escrita: "sim, corrigimos, sim pensamos em proficiência. Não é proficiência por proficiência, correção por correção, mas preparação para usos da língua em diversos contextos e para se prepararem como professores".

Em geral, há uma busca por novas bases teóricas ou, ao menos, um processo de familiarização com questionamentos recentes, incluindo trabalhos de pesquisadores como Canagarajah (2013; 2014), Ortega (2013; 2014), McKay (2002), Matsuda (2012; 2017), além dos realizados no contexto brasileiro, anteriormente citados. Percebi, ainda, que não houve referências às críticas e concepções mais radicais quanto ao próprio conceito de língua, tal como as feitas por Pennycook e Makoni (2007).

Especificamente quanto ao entrelaçamento entre trajetórias profissionais e construção de atitudes pedagógicas frente às mudanças envolvendo a língua inglesa hoje, observo duas situações: uma em que se desenvolvem atitudes diferentes na pesquisa e no ensino (com conflito latente ainda a ser enfrentado) e outra em que há uma aproximação das atitudes nos dois 
campos, com esforços para encaminhar tanto a pesquisa quanto a docência considerando a mudança de status do inglês e as críticas a conceitos como o de falante nativo.

Como exemplos da primeira situação, considero as participantes 2 e 4 , que iniciaram e continuaram com suas pesquisas dentro da tradição construída a partir do conceito de falante nativo monolíngue. No entanto, em sala de aula, a consciência da mudança do status da LI influencia nas reflexões realizadas com suas turmas, na escolha de materiais, na flexibilidade quanto a padrões de língua e na ênfase dada para a consideração dos contextos de uso da língua.

A participante 2 relatou que ao longo de seus estudos, até o doutorado, o conceito de falante nativo como parte da base teórica não era questionado. Mais recentemente, familiarizouse com conceitos como inteligibilidade e legitimidade. $\mathrm{O}$ falante nativo se transformou em mais uma opção a ser considerada, levando-se em conta principalmente o objetivo do aprendiz: "A meta do native-like continua válida? De novo - se o aluno precisar ou achar válido, pode ser válido." Nas pesquisas que desenvolve, em torno de alternativas colaborativas de ensino e aprendizagem, o questionamento ainda não se encontra aflorado. Suas reflexões, entretanto, permitiram observar questões importantes na sua trajetória como aprendiz do inglês. Lembrou que o ensino de inglês que teve na escola regular se pautava na gramática e na tradução, não se falava em inglês e "nunca escreveu uma frase sobre [si mesma]", uma afirmação que abre perguntas sobre o papel identitário que o inglês pode ou não desempenhar em diferentes fases de sua vida. Adquiriu, com estudos para certificados de proficiência e vivência no exterior, "um inglês bonito com British accent", e sabe que até hoje permanece a autocobrança de uso da língua padrão. Durante a entrevista, a participante demonstrou uma atitude leve e entusiasmada ao relatar a forma intricada como a aprendiz, a pesquisadora e a docente constroem trajetórias diferenciadas e em meio a conflitos e cobranças.

Quanto à participante 4, ao responder sobre seu contato com a discussão sobre o novo status do inglês no mundo afetaram suas reflexões e sua prática como pesquisadora e docente, estava consciente das escolhas que fazia:

Não é um tema que me interessa particularmente como pesquisadora e não baseio minhas pesquisas para nenhuma teoria que tenha em conta ELF. Como docente, especialmente nas matérias de língua, tento trazer mais a discussão sobre variedades de inglês e apresentar distintas variedades para os alunos e diminuir o foco de falante nativo como o único modelo a seguir. Na minha pesquisa, porém, foco mais em acurácia da pronúncia que em inteligibilidade, tema que é estudado mais no contexto de ELF.

O momento de sua trajetória profissional é o de adaptação a um novo contexto de trabalho, tendo começado a trabalhar na universidade mais recentemente. Mesmo o contato com as discussões sobre a língua inglesa hoje é também relativamente recente (cerca de cinco anos). Está ainda conhecendo o curso de graduação, mas expressou interesse em ministrar alguma disciplina em que pudesse tratar de variedades da língua inglesa.

Quanto à segunda situação, observo nas participantes 3, 5 e 7 que suas trajetórias permitiram a construção de atitudes mais congruentes como pesquisadoras e professoras. A participante 3 usa hoje o termo ILI e a noção de inteligibilidade a de compreensibilidade como parâmetros para discutir a produção oral e as implicações pedagógicas para a aprendizagem de pronúncia. Considera que língua franca "tem outras conotações desde o início de seu uso" e que termos como global ou mundial soam "pretensiosos". A participante 5 chegou à mesma escolha terminológica, ILI, baseada no interesse pelos desafios de repensar as teorias de aquisição de línguas. Afirmou que pesou também uma questão prática: queria se afastar do termo ILF pela conturbada história de suas formulações teóricas, carregada de críticas quanto à postulação inicial de um cerne estruturador do inglês como língua franca (língua franca core) e a dificuldades de conciliação com concepções de multi e translinguismo. Já a participante 7 
Volume 16 - Número 1 - jan/jul de 2021

optou por usar o termo World Englishes (WE) por considerá-lo adequado para a área de pesquisa de seu interesse, literaturas de língua inglesa e o ensino de inglês.

Ela (P7) recuperou o momento em que começou a se familiarizar com a problematização do status do inglês, relatando a forma como isso se refletiu na sua atuação como docente e pesquisadora:

Eu lembro de ter tido algumas conversas com um ex-colega de trabalho [...] na universidade [onde trabalhava] e isso foi em 2002, 2003. E eu lembro que foi ele quem primeiro mencionou o livro do David Crystal, English as a Global Language. E ele tinha o livro e me emprestou. Tenho certeza que esse foi o primeiro contato que eu tive, mais formal, [...] sobre essa questão do status do inglês como língua global. E me chamou a atenção porque até então os termos que normalmente eu encontrava nas referências que eu lia era inglês como segunda língua ou inglês para falantes de outras línguas [...] Com certeza, após ter lido esse livro eu passei a procurar mais referências a respeito [...] e passei sim a tomar um pouquinho mais de cuidado na forma como eu colocava as questões ou levava textos para serem discutidos em sala de aula. $\mathrm{Na}$ época, 2002, 2003, 2004, eu era professora da graduação [...] e eu estava trabalhando com a formação inicial e continuada de professores, eu atuava na graduação e num curso de especialização daquela universidade. E eu lembro que mesmo tendo sido convidada a dar um módulo específico na pósgraduação sobre ensino de literatura, eu lembro de ter tomado o cuidado pra levar textos escritos em inglês, mas por autores cuja segunda língua era o inglês, não era a língua materna deles e de ter colocado isso como sendo algo positivo, que os próprios professores que estavam o curso de especialização na época poderiam adotar como sua prática. Então, sim, essa consciência sobre esse uso do termo que estava sendo difundido na época teve consequências na minha prática tanto como pesquisadora como na minha prática como docente. E eu lembro que isso se intensificou a partir de 2010, 11, quando eu entrei em contato com algumas entrevistas gravadas com o autor, David Crystal, sobre esses termos, mas aí outros termos já estavam pipocando também.

A participante 3 entrou em contato com os questionamentos em torno do status da língua inglesa enquanto fazia doutorado, ao assistir a uma palestra em um evento. Ela relatou ter ficado "um pouco contrariada" com as questões que foram levantadas, mas que começou a ler sobre o tema, familiarizando-se, por exemplo, com as pesquisas de Jenkins e sua proposta inicial de lingua franca core (JENKINS, 2000). Percebeu que isso teve um impacto inicial em sua autopercepção como aprendiz da língua, já que trazia uma experiência de aprendizagem em que o falante nativo era apresentado como norma. Percebeu, ainda, que esse tipo de questionamento não era realizado na área de ensino de português como segunda língua, na qual também atuava. Quanto ao impacto para sua atuação docente, explica:

[...] na minha prática de sala de aula, isso se reflete muito no fato de que eu busco deixar claro para os alunos a noção de variação, a noção de que saber falar mais de uma língua nos torna diferentes e portanto nossa linguagem é diferente, e a gente não deve se comparar a uma pessoa monolíngue que fala sua língua ou falante nativo porque uma pessoa que fala mais de uma língua tem outras características e eu busco sempre que possível trazer algumas noções de variação e sempre tentar desmistificar no aluno, quanto eles perguntam, como perguntaram ainda nesta semana, isso é o certo ou isso tá errado, eu sempre digo a eles eu não gosto dos termos certo e errado porque depende muito do que você está fazendo, como você está usando a linguagem, de onde você está usando a linguagem [...] não existe só um padrão, não existe 
Volume 16 - Número 1 - jan/jul de 2021

só uma forma e de quando a gente fala uma língua como segunda, terceira, outras línguas, existem outros padrões e a gente se adequa e a gente utiliza esses outros padrões desde que a gente não comprometa a comunicação, que a gente consiga estabelecer comunicação [...]

Quanto ao impacto na sua atuação como pesquisadora, a participante 3 relatou a mudança na base conceitual para continuar lidando com a descrição da pronúncia de aprendizes de línguas:

[...] quando ficou claro pra mim a questão que o padrão nativo não é o único padrão e eu comecei a ler sobre estudos sobre inteligibilidade e compreensibilidade, na minha pesquisa também deu uma guinada. Eu continuo fazendo pesquisa semelhante a que eu fazia antes, de descrição linguística da pronúncia de aprendizes brasileiros de inglês ou de aprendizes de português como segunda língua. No entanto, grande parte da minha pesquisa passou a abordar, e das minhas orientações também, passaram a abordar a questão da inteligibilidade e da compreensibilidade como parâmetros para discutir a produção oral dos alunos e as implicações pedagógicas para a aprendizagem de pronúncia dos alunos, então usar os parâmetros de inteligibilidade e de compreensibilidade em vez dos parâmetros do, igual à produção do falante nativo. Então acho que isso é um reflexo de incorporar essas discussões [...]

A participante 5, além de ter desenvolvido sua pesquisa de doutorado enfocando o conceito de inglês como língua global e explorando o contexto brasileiro, vem desde então publicando pesquisas sobre as mudanças conceituais em torno da língua inglesa e as consequentes problematizações pedagógicas e experimentando tanto na graduação quanto na pós-graduação práticas pedagógicas com esse novo embasamento teórico. Traz, portanto, uma gama de experiência docente e de pesquisa que apontam para uma posição amadurecida quanto às discussões sobre a expansão da língua inglesa no mundo e suas implicações para o ensino da língua e a formação de professores. De fato, na entrevista, ela relatou ter saído confiante do doutorado. Contudo, revelou que encontrou contextos que a desafiaram e nos quais continua procurando encontrar caminhos possíveis:

Tenho tentado incorporar o que estudei nas disciplinas que leciono, encontrar brechas. Como na disciplina de escrita, onde a questão da identidade emerge frequentemente nas discussões e acaba tocando no status da língua e na noção de ownership. Procuro conversar, trazer pra um nível de reflexão consciente.

Em uma ocasião posterior em que pudemos retomar alguns tópicos da entrevista, ela explicou que para esse tipo de prática reflexiva o que é de fato importante é uma mudança atitudinal. A negociação que se faz em sala de aula, voltada para um aumento de consciência linguística, baseia-se numa postura estratégica, colaborativa e solidária. Isso se conectou com o exemplo que ela havia dado na entrevista: trabalhando com a produção escrita e preocupado com a formação de futuros professores, abriu um espaço para a elaboração de rubricas para avaliação feita em colaboração com os próprios alunos. Era necessário levar em consideração as expectativas sociais quanto ao que atingir dentro de determinado gênero, por exemplo, resenhas acadêmicas, encarando o texto não como uma produção individual, mas como construção dialógica, envolvendo inclusive a revisão por colegas. Nessas práticas, encontramse necessariamente em negociação o que se toma como inteligível e legitimado. É claro que esse tipo de reflexão se expande para toda a prática de linguagem, não se restringindo ao uso da língua inglesa. Ao reencontrar alguns de seus alunos da graduação ingressando na pós- 
graduação, ela pode contar com eles como colaboradores para um aprofundamento dos questionamentos conceituais em torno de língua, ensino e aprendizagem.

Apresento esses dois casos sem a intenção de julgar se uma combinação de trajetórias é melhor do que outra como resposta aos desafios da expansão do inglês e dos recentes questionamentos sobre seu status. É necessário sublinhar que se tratam de respostas responsáveis dentro dos desenhos únicos de cada entrelaçamento de trajetórias e que são trajetórias sendo desenhadas, abertas, portanto, a outras direções, e sempre contingenciais. Apontei duas possíveis trajetórias de dentro do nexo de trajetórias que cada um constrói. Foi o suficiente para perceber que não é possível tratar de atitudes pedagógicas sem considerar a construção de outras atitudes dentro do contexto profissional do docente universitário, tal como a atitude enquanto pesquisadores - elas se imbricam, podendo se fortalecer mutuamente, provocar conflitos, exigir separações, manter estados de tensão, se modificar.

Cruzando a leitura das entrevistas e a análise dos currículos (que incluíam por vezes a leitura de parte das publicações das docentes) e as leituras do referencial teórico, o que chamou atenção também foi perceber como as chamadas "viradas" na linguística aplicada (social, multilíngue, afetiva) ocorreram em curto espaço de tempo de forma que todas as professoras entrevistadas sofreram ou estão sofrendo pressões e torções conceituais. A maioria teve um aprendizado de línguas baseado na abordagem comunicativa, algumas ainda aprenderam o inglês por métodos de tradução e gramática e audiovisual. Nas primeiras etapas de sua formação como pesquisadoras (mestrado) utilizaram teorias construídas principalmente a partir dos pressupostos do monolinguismo como padrão natural e da noção de falante nativo. Parte das contradições e tensões enfrentadas pelas participantes derivam deste contexto intenso de mudanças teórico conceituais.

É positivo, para mim, observar que como parte das atitudes desenvolvidas por elas há, junto com a inevitável e provocadora ansiedade, ponderação e entusiasmo. A ponderação permite dar continuidade ao que já foi iniciado e examinar as alternativas que se abrem sem se impor cobranças apenas desgastantes. O entusiasmo compartilhado faz lembrar da paixão que move a construção do conhecimento e que, neste caso, se encontra frequentemente na sensação prazerosa de vivermos mergulhados na linguagem.

\section{Considerações finais}

Em 2014, Bordini e Gimenez (p.33) concluíram sua metassíntese dos estudos de inglês como LF no Brasil com as seguintes considerações:

Em um primeiro momento, portanto, parece que estamos ainda tentando elaborar os sentidos da língua inglesa em nosso país, para derivarmos implicações para seu ensino. As preocupações pedagógicas, refletidas na preferência por estudos com alunos e professores de Inglês, são pertinentes e tomam como foco a questão de qual inglês queremos aprender e para quê.

Quase cinco anos depois, continuamos desenvolvendo essas elaborações de sentidos, em um período de intensa desconstrução de vários pressupostos e ansiedade pelas implicações pedagógicas. Os desenvolvimentos teóricos a partir das visões multilíngue e translíngues, ainda que em estágio inicial, tanto na área sociocultural quanto na cognitiva, começam a dar chão para a lenta (des)construção de conhecimento sobre a aprendizagem e uso de repertórios linguísticos.

Dentro desse contexto, continuamos construindo nossos complexos nexos de trajetórias, questionando nossas atitudes como docentes, pesquisadores e formadores de professores, e 
Volume 16 - Número 1 - jan/jul de 2021

procurando manter nosso entusiasmo principalmente em tempos de retrocessos políticos que atingem toda a atividade docente e de pesquisa no Brasil hoje.

\section{Referências}

BERREDO, G.; GIL, G. Teachers' and student-teachers' perceptions of English as a lingua franca (ELF) and the teaching of culture in the language classroom. In: GIMENEZ, T.; EL KADRI, M. S.; CALVO, L.C. S (Org.). English as a Lingua Franca in Teacher Education: a Brazilian perspective. Berlin: De Gruyter, 2018, v. 1, p. 115-136.

BORDINI, M; GIMENEZ, T. Estudos sobre inglês como língua franca no Brasil (20052012): uma metassíntese qualitativa. Signum: Estudos da linguagem, v.17, n.1, 2014, p. 1043. Disponível em: https://www.uel.br/revistas/uel/index.php/signum/article/view/17389. Acesso em: 28 jan. 2017.

BROWN, J.; MCKAY, S. Teaching and Assessing EIL in Local Contexts Around the World. New York: Routledge, 2016.

CANAGARAJAH, S Translingual Practice: global English and cosmopolitan relations. Routledge, 2013.

CANAGARAJAH, S. In search of a new paradigm for teaching English as an International Language. TESOL Journal, v.5, n.4, p. 767-785, 2014. Disponível em:

https://onlinelibrary.wiley.com/doi/10.1002/tesj.166. Acesso em: 10 mai. 2017. CONNELLY, F. M.; CLANDININ, D. J. Shaping a Professional Identity: stories of educational practice. New York: Teachers College Press, 1999.

DENARDI, D. A. C.; GIL, G. How do I see myself? What do I want to become? A study on English as an additional language teachers' identity reconstruction. Trabalhos em

Linguística Aplicada, Campinas, n.54, v.1, jan./jun. 2015, p. 137-160. Disponível em: https://www.scielo.br/j/tla/a/CMVkY5LNgpnGk3rS7MnGHkx/?lang=en. Acesso em: 23 out. 2017.

FIGUEIREDO, E. H. D. Second language acquisition in Brazil since the social turn. Revista Brasileira de Linguística Aplicada, v. 18, p. 1-27, 2018a. Disponível em: https://doi.org/10.1590/1984-6398201812420. Acesso em: 27 dez. 2018. FIGUEIREDO, E. H. D. Globalization and the global spread of English: concepts and implications for teacher education. In: Gimenez, T.; El Kadri, M. S.; Calvo, L. C. S. (Org.). English as a Lingua Franca in Teacher Education: A Brazilian Perspective. Berlin: De Gruyter Mouton, p. 31-52, 2018b.

FIGUEIREDO, E. H. D.; SANFELICI, A. Addressing Culture from an EIL Perspective in a Teacher Education Course in Brazil. In: Aya Matsuda. (Ed.). Preparing Teachers to Teach English as an International Language. Bristol: Multilingual Matters, 2017. p. 147156. Disponível em: https://doi.org/10.21832/9781783097036-012. Acesso em: 20 fev. 2018. DUBOC, A. P. M. Atitude Curricular: Letramentos Críticos nas brechas da formação de professores de inglês. Tese de doutorado. Programa de Pós-Graduação em Estudos Linguísticos e Literários em Inglês do Departamento de Línguas Modernas da Faculdade de Filosofia, Letras e Ciências Humanas da Universidade de São Paulo: USP. 2012. 246 f. Disponível em: https://www.teses.usp.br/teses/disponiveis/8/8147/tde-07122012-102615/ptbr.php. Acesso em: 17 abr. 2017.

El KADRI, M. S. Inglês como língua franca: um olhar sobre programas disciplinares de um curso de formação inicial de professores de inglês. Entretextos, Londrina, v.10, n.2, p.64-9, jul./dez. 2010. Disponível em:

https://www.uel.br/revistas/uel/index.php/entretextos/article/view/7966. Acesso em: 17 dez. 2017. 
FOGAÇA, F. C. Conversa com Francisco Carlos Fogaça. In: Aragão, R. C. (Org.). Conversas com (mais) Formadores de Professores de Línguas: avanços e desafios. Campinas: Pontes Editores, 2016. p. 109-125.

FOUCAULT, M. As palavras e as coisas. São Paulo: Martins Fontes, 2000.

GEE, J. P. Identity as an Analytic Lens for Research in Education. Review of Research in Education, Washington, v. 25, n. 1, p. 99-125, 2000. Disponível em:

https://journals.sagepub.com/doi/pdf/10.3102/0091732X025001099. Acesso em: 15 mar. 2009.

GIMENEZ, T.; EL KADRI, M.; CALVO, L. C. S. (Org.). English as a Lingua Franca in Teacher Education: a Brazilian Perspective. Berlin: De Gruyter Mouton, 2018. GIMENEZ, T.; CALVO, L.C.S.; EL KADRI, M.S. (Org.). Inglês como Língua Franca: ensino-aprendizagem e formação de professores. Campinas, SP: Pontes Editores, 2011. HALU, R. C.; FOGAÇA, F. C. A expansão da língua inglesa e seu impacto nos professores universitários de inglês em cursos de Letras: um diálogo reflexivo. Revista X, v.13, p.1-14, 2018. Disponível em: https://revistas.ufpr.br/revistax/article/view/61246. Acesso em: 10 dez. 2018.

JENKINS, J. Repositioning English and multilingualism in English as a Lingua Franca. Englishes in Practice, v.1, n.3, 2015, p.49-85. Disponível em:

https://www.sciendo.com/article/10.1515/eip-2015-0003. Acesso em: 18 jun. 2017.

JENKINS, J. The Phonology of English as an International Language: new models, new norms, new goals. Oxford: Oxford University Press, 2000.

JORDÃO, C. M. English as a foreign language, globalisation and conceptual questioning. Globalisation. Societies and Education, v.7, n.1, p. 95-107, 2009. Disponível em: https://www.tandfonline.com/doi/full/10.1080/14767720802677390. Acesso em: 12 mar. 2016.

JORDÃO, C. M. ILA - ILF - ILE - ILG: Quem dá conta? RBLA, Belo Horizonte, v. 14, n.1, p. 13-40, 2014. Disponível em: https://doi.org/10.1590/S1984-63982014000100002. Acesso em: 20 set. 2019.

JORDÃO, C. M; MARTINEZ, J. Z. Entre as Aspas das Fronteiras: internacionalização como prática agonística. In: Rocha, C. H.; Braga, D. B.; Caldas, R. R. (Org.). Políticas linguísticas, ensino de línguas e tecnologia em tempos de globalização e internacionalização.

Campinas: Pontes Editores, 2015. p. 61-88.

MACHADO, F. R.; GIL, G. The processes of construction, deconstruction and reconstruction of an IFSC English language teacher's professional identity. DELTA. Documentação de Estudos em Linguística Teórica e Aplicada (PUC-SP), São Paulo, v.33, p.383-411, 2017. Disponível em: https://www.scielo.br/j/delta/a/nQ35wGBM7JjSCCm4TNGTTcr/?lang=en. Acesso em: 19 mar. 2018.

MAKONI, S.; PENNYCOOK, A. (Eds). Disinventing and Reconstituting Languages. Clevedon: Multilingual Matters, 2007.

MARTINEZ, R. "Specially in the last years": evidence of ELF and non-native English forms in international journals. Journal of English for Academic Purposes, v. 33, p. 40-52, 2018. Disponível em:

https://www.sciencedirect.com/science/article/abs/pii/S1475158518300389?via\%3Dihub. Acesso em: 18 ago. 2018.

MATSUDA, A. (Org.). Preparing Teachers to Teach English as an International Language. Bristol: Multilingual Matters, 2017.

MATSUDA, A. Principles and Practices of Teaching English as an International Language. Bristol: Multilingual Matters, 2012.

MCKAY, S. L. Teaching English as an International Language: rethinking goals and approaches. Oxford: Oxford University Press, 2002. 
MOTT-FERNANDEZ, C.; FOGAÇA, F. C. Inglês como língua internacional na universidade: rejeição e objeto de desejo. Linguagem \& Ensino, Pelotas, v.12, n.1, p.195225, jan/jun 2009. Disponível em:

https://periodicos.ufpel.edu.br/ojs2/index.php/rle/article/view/15707/9892. Acesso em: 14 mar. 2017.

ORTEGA, L. SLA for the 21st century: disciplinary progress, transdisciplinary relevance, and the bi/multilingual turn. Language Learning, v. 63, n.1, p. 1-24, 2013. Disponível em: https://onlinelibrary.wiley.com/doi/10.1111/j.1467-9922.2012.00735.x. Acesso em: 16 abr. 2017.

ORTEGA, L. Ways forward for a bi/multilingual turn for SLA. In: May, S. (Ed.). The Multilingual Turn: implications for SLA, TESOL, and Bilingual Education. UK: Routledge, 2014. p. 32-52.

REGIS, H. F.; GIL, G. Student-teachers' perceptions of English as a Lingua Franca and its influence in times of globalizations. In: III Congresso Internacional da Associação Brasileira de Professores Universitários de Inglês - ABRAPUI, 2012, Florianópolis. Caderno de Resumos, 2012. p. 285-285.

ROSA FILHO, J.A.; VOLPATO, M.; GIL, G. English as a Lingua Franca: Representations and practices of English learners and teachers in Brazil. In: GIMENEZ, T.; EL KADRI, M. S.; CALVO, L.C. S. (Org.). English as Lingua Franca in Teacher Education: a Brazilian perspective. Berlin: De Gruyter, 2018, v. 1, p. 137-158.

SIQUEIRA, S.; GIMENEZ, T.; EL KADRI, M. S.; CALVO, L. C. S. English as a lingua franca and teacher education: critical educators for an intercultural world. In: GIMENEZ, T.; EL KADRI, M. S.; CALVO, L.C. S. (Org.). English as a Lingua Franca in Teacher

Education. Berlim, Alemanha: De Gruyter, 2018. p. 87-114.

WENGER, E. Communities of Practice: Learning, meaning, and identity. Cambridge: Cambridge University Press, 1988. 